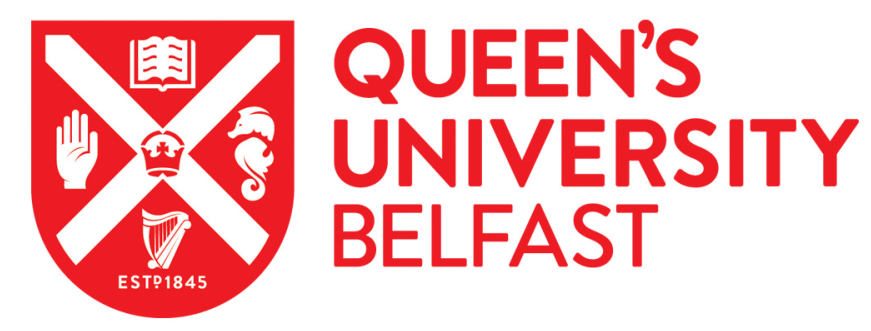

\title{
Effect of Cyclic Carbonation on Chloride Ingression in GGBS Concrete
}

Backus, J., \& McPolin, D. (2016). Effect of Cyclic Carbonation on Chloride Ingression in GGBS Concrete. ASCE Journal of Materials in Civil Engineering. https://doi.org/10.1061/(ASCE)MT.1943-5533.0001529

Published in:
ASCE Journal of Materials in Civil Engineering

Document Version:

Peer reviewed version

Queen's University Belfast - Research Portal:

Link to publication record in Queen's University Belfast Research Portal

Publisher rights

(C) 2016 American Society of Civil Engineers

\section{General rights}

Copyright for the publications made accessible via the Queen's University Belfast Research Portal is retained by the author(s) and / or other copyright owners and it is a condition of accessing these publications that users recognise and abide by the legal requirements associated with these rights.

Take down policy

The Research Portal is Queen's institutional repository that provides access to Queen's research output. Every effort has been made to ensure that content in the Research Portal does not infringe any person's rights, or applicable UK laws. If you discover content in the Research Portal that you believe breaches copyright or violates any law, please contact openaccess@qub.ac.uk. 
Effect of Cyclic Carbonation on Chloride Ingression in GGBS Concrete

Jonathon Backus and Daniel McPolin

Abstract: Carbonation and chloride ingress are the two main causes of corrosion in reinforced concrete structures. An investigation to monitor the ingress of chlorides and the effect of carbonation on chloride ingression during an accelerated 12 month cyclic wetting and drying exposure regime that simulates conditions in which multiple mode transport mechanisms are active was conducted on ground granulated blast furnace slag (GGBS) concrete. The penetration of chloride and carbon dioxide was evaluated using water and acid soluble chloride profiles and phenolphthalein indicator, respectively. The results indicated that when chloride and carbon dioxide ingress concomitantly the effects can be adverse. Carbonation has a detrimental effect on the binding capacity of the concrete, increasing the concentration of free (water soluble) chlorides. This contributed to greater concentration and greater penetration of chlorides and thus an increased corrosion risk

Introduction

Corrosion of reinforcing steel caused by the ingression of chlorides or carbonation and the subsequent deterioration is responsible for over $50 \%$ of deterioration of concrete structures within the United Kingdom. In Europe it has been estimated that $50 \%$ of the total construction budget is spent on the inspection, maintenance, and repair of concrete structures (Tilly and Jacobs 2007), while corrosion of reinforcement required an annual expenditure of US\$8.3 billion in the United States (Tilly 2011). The current European [BS EN 206 (BSI 2013)] and American [ACI 318 (ACI 2011)] standards provide guidelines for designing structures to combat each of these deterioration mechanisms individually, but numerous scenarios where two or more of these mechanisms may occur simultaneously exist. Scenarios such as marine structures (Fig. 1) or structures exposed to deicing salts (Fig. 2) could be exposed to cycles of chloride (attack) and carbonation that are not specifically accounted for in the standards.

Other research has looked at the effect of carbonation on chloride contaminated concrete (Goæi and Guerrero 2003; Nagatakii and Ohga 1992; Suryavanshi and Swamy 1996) while Montemor et al. (2002) conducted a cyclic experiment with pulverized fly ash (PFA). The use of ground granulated blast furnace slag (GGBS) is becoming more widespread due to its environmental credentials and pore modification properties (Bostanci et al. 2015; Osborne 1999). It is also used in environments with high levels of chlorides due to its chloride binding capabilities (Dhir et al. 1996; Luo et al. 2003). However, it is widely known that pozzolanic cements have a lower $\mathrm{pH}$ and subsequently lower resistance to carbonation (Bostanci et al. 2015; Osborne 1999).

Chloride Ingression

Chlorides occur naturally in seawater at concentrations between 4 and $20 \mathrm{~g}=\mathrm{L}$ (Buenfeld and Newman 1984) and are also commonly present as sodium chloride used in deicing salts. The ingress of chlorides is caused generally by three mechanisms: Absorption, permeation, and diffusion. It is often the measurement of the coefficients of these transport mechanisms which are used to define durability of concretes, though it should be noted that it is often a combination of the mechanisms which lead to the chloride ion movement. It may be argued that a more realistic approach is to define an apparent diffusion coefficient that will include all of the transport phenomena based on obtained chloride profiles within the concrete rather than pure diffusion. The movement of liquid, 
which may contain aggressive agents such as carbon dioxide or chloride ions, can be described as convection and can be caused by permeability and/or absorption. The pore network enables the transportation of solids, liquids, and gases through the cementitious material. As the binder type influences the microstructure of the hydrated cement paste, it will have an influence on its permeation properties. Furthermore, due to the structure of hydrated cement paste, chlorides within concrete can exist in two forms: Free chlorides and bound chlorides. Free chlorides are dissolved in the concrete pore solution while bound chlorides are either physically bound (adsorbed onto the surface of the gel pores) or chemically bound (incorporated in the products of hydration) (Kropp 1995; Neville 1995a, b). These two types of chlorides (free and bound) normally exist together to maintain a chemical equilibrium (Kropp 1995; Neville 1995b; Nilsson 1996). However, it is generally accepted that the free chlorides contained within the pore solution are those that can cause corrosion. It is also accepted that the amount of chlorides which are bound physically and chemically is affected by mineral admixtures (Arya and Xu 1995; Lu et al. 2002) and pH (Suryavanshi and Swamy 1996). The incorporation of GGBS creates more sites for physical binding, through the increase of calcium silicate hydrate (C-S-H), while the chemical composition (i.e., the increase in aluminate contents) (Table 1) contributes toward an increased capacity for chemical binding (Yuan et al. 2009; Thomas et al. 2012).

\section{Carbonation}

Carbon dioxide ( $\mathrm{CO} 2)$ is a component of air, existing in the atmosphere at a concentration of $0.03 \%$. However, depending on localized conditions, concentrations may reach as high as $1 \%$ (Neville 1995b). When carbon dioxide diffuses into the concrete, it dissolves in the pore fluid and then reacts with calcium hydroxide $(\mathrm{CaOH})$ to form calcium carbonate (CaCO3) and water (Parrott 1987).

Calcium carbonate is less soluble in water than calcium hydroxide and has a greater volume than the original hydrate; it has the potential to block the pores and reduce permeability (Parrott 1987). The removal of calcium hydroxide from the pore fluid has the effect of reducing the $\mathrm{pH}$ of the concrete, and when the $\mathrm{pH}$ of the concrete drops below 11.5 (Schiessl 1988) the passive oxide film that protects the reinforcement becomes unstable and the reinforcement becomes susceptible to corrosion. The addition of GGBS lowers the initial pH, the quantity of calcium hydroxide (Table 1 ) available for consumption, and the permeability of the concrete (Parrott 1987).

Interaction of Chloride Ingression and Carbonation

Wetting and drying cycles are the most severe environments for corrosion caused by carbonation or chloride ingression and also the most likely scenario in which combined deterioration will occur (Bamforth et al. 1997; Neville 1995b; Montemor et al. 2002). The formation of calcium carbonate due to carbonation may result in a less permeable concrete and reduce the rate of ingression of both chlorides and further carbon dioxide. However, studies show that the reduction in $\mathrm{pH}$ also decreases the stability of Friedel's salt (Glass et al. 2000) as well as affecting the hydroxide content in the pore solution which brings about an increase in free chloride content. This increase in free chloride content may increase the concentration gradient and accelerate the ingress of chlorides or the increase of chlorides may result in the critical chloride threshold being reached at the reinforcement. 
Aims of the Study

The primary aim of this project is to assess whether the cyclic exposure of GGBS concrete to cyclic chloride and carbon dioxide environment increases the corrosion risk compared to the chloride only exposure accounted for in the standards.

\section{Experimental Procedure}

Specimen Preparation

A single GGBS mix was used in this study incorporating 50\% Portland cement (PC) and 50\% GGBS. The details of this mix are shown in Table 2 . The chemical and physical compositions are shown in Table 1. A water-binder ratio of 0.5 was chosen to give workability (slump cone) in the range of 10$50 \mathrm{~mm}$. The aggregate binder ratio was 5 . Slabs of size $230 \times 230 \times 80-\mathrm{mm}$ were cast for coring specimens along with ponding slabs of dimensions $230 \times 230 \times 100-\mathrm{mm}$ and $100 \mathrm{~mm} 3$. The slabs and cubes were manufactured according to BS 1881:125 (BSI 1986) using a pan mixer. They were cast and removed from the moulds $24 \mathrm{~h}$ after casting.

Fig. 1. Coastal structure with representative exposure zones (adapted from Mehta and Monteiro 2006)

Fig. 2. Road structure exposed to deicing salts and water

Table 1. Chemical Composition and Physical Properties of Binders

\section{Curing and Preparation}

After demolding, the slabs were stored in a water bath $\left(201^{\circ} \mathrm{C}\right)$ for 3 days (BSI 2009). They were then removed and transferred to a constant temperature room with ambient conditions of $201^{\circ} \mathrm{C}$ and $551 \%$ relative humidity $(\mathrm{RH})$ until they were 28 days old. After 28 days, a total of nine $60-\mathrm{mm}-$ diameter cylinder cores were cut from each of the coring slabs manufactured. Three cubes were tested at 28,60 , and 90 days to monitor hydration of the GGBS to reduce the variable of continued hydration.

The cores were cut from the slabs with an external water source applied as a coolant during coring. If coring was carried out after exposure to the chloride environment, it would have affected the chloride distribution. After coring, the cylinders and ponding slabs were coated on all bar the ponding surface with three coats of epoxy emulsion (Sikaguard 680), forming a barrier which prevented any lateral ingress of chloride ions or carbon dioxide. To facilitate ponding, a $60-\mathrm{mm}$ diameter pipe of length $50 \mathrm{~mm}$ was placed over the top of each core forming a reservoir in which the ponding solution was contained. The joint between the pipe and the core was tight and was packed with silicone sealant to ensure no leakage during ponding (Fig. 3). The samples were then returned to the constant temperature and humidity room to continue curing for a minimum of 90 days to allow complete hydration.

\section{Exposure Regime}

To create an accelerated exposure regime that was representative of natural conditions while facilitating multiple mode deterioration, a wetting and drying cycle was chosen. A similar regime has been used previously for chloride ingression by Polder and Peelen (2002) and is representative of 
the splash zone which Bamforth et al. (1997) identified as the most severe. The regime was optimized by monitoring the humidity development using embedded probes at discrete depths within the concrete over a two week period at varying temperatures and humidity. The selected ponding regime comprised 1 day ponding in the chloride solution followed by 13 days drying at $40^{\circ} \mathrm{C}$ and $20 \%$ relative humidity (RH) (Fig. 4). Two exposure regimes were selected for testing. These were $2.0 \%$ sodium chloride solution with atmospheric $\mathrm{CO} 2$ and $2.0 \%$ sodium chloride with $5 \% \mathrm{CO} 2$. These cycles were repeated every fortnight (14 days) until testing.

Testing

Testing of the samples was carried out after 4, 12, 24, 36, and 48 weeks. To monitor the ingress of the carbon dioxide and chloride along with their chemical and physical effects on the concrete a variety of tests were carried out.

Phenolphthalein Indicator Solution

The aim of the phenolphthalein indicator was to gain an insight into the movement of the carbonation front. It is a quick, simple visual test that highlights the depth at which the $\mathrm{pH}$ changes illustrative of the depth of carbonation. Indicator solution was made up according to BS EN 14630 (BSI 2006) and sprayed onto a freshly split $60 \mathrm{~mm}$ concrete cylinder. Using a ruler, the minimum, maximum, and average depths for the point that the indicator changed color were measured and recorded.

\section{PH Profiles}

Dust was obtained from a 60-mm cylinder at depth increments of $0-1,1-2,2-3,3-4,4-5 \mathrm{~mm}, 5-$ $7.5,7.5-10,10-12.5,12.5-15,15-20,20-25$, and 20-30 mm using a profile grinder. One gram of this dust was weighed into a small plastic bottle and $10 \mathrm{~mL}$ of deionized water was added (McPolin et al. 2007). The plastic bottles were then placed in a rotator and the solution mixed for $24 \mathrm{~h}$. After $24 \mathrm{~h}$, a Gelplas reference combination $\mathrm{pH}$ electrode was used to obtain a $\mathrm{pH}$ value. The use of water will likely dilute the $\mathrm{pH}$ values and therefore $\mathrm{pH}$ values are only relative and used for comparison purposes.

\section{Water Soluble Chloride Profiles}

The samples that had been dissolved and agitated for the $\mathrm{pH}$ profiles were then placed in a centrifuge for $5 \mathrm{~min}$ at 5,000 revolutions per minute $(\mathrm{rpm})$ to separate the solids from the solution. This $10 \mathrm{~mL}$ solution was then placed in $80 \mathrm{~mL}$ of deionized water and analyzed using potentiometric titration with silver nitrate and a potassium nitrate reference electrode to obtain the water soluble chloride content.

Acid Soluble Chloride Profiles

The acid soluble profiles were obtained with $1 \mathrm{~g}$ of sample using nitric acid and potentiometric titration according to the procedure set out in BS EN 14629 (BSI 2007). 
Results

pH Results

The $\mathrm{pH}$ profiles in Fig. 5 illustrate that significant carbonation has occurred in the cyclic chloride and carbon dioxide exposure regime. The results correspond well with literature and the phenolphthalein indicator test. They indicate that the uncarbonated $\mathrm{pH}$ of the GGBS concrete is around 12, dropping to a $\mathrm{pH}$ in the range of 9.5-10 in the carbonated concrete. As the carbonation progresses, a distinct carbonation front can be observed, illustrating the degree that carbonated concrete decreases with depth.

Chloride Profiles

The 6 and 12 month acid soluble chloride profiles for the chloride only exposure are shown in Fig. 6 as solid lines. The general trend is a high surface concentration followed by a dip, with an increase to a maximum concentration at increasing depths with time, before a final gradual decrease toward zero in both exposure durations. This profile is as would be expected from the external cyclic ponding source (Ye et al. 2012) as the dry surface rapidly absorbs the chloride solution and then sodium chloride crystalizes on the surface when the solution is removed, creating a higher concentration. The water soluble chloride profiles for the chloride only exposure are also plotted on Fig. 6 as dotted lines and follow the same shape as the acid soluble profiles but at a lower concentration level. This is as would be expected as they are a subset of the total (acid soluble) chloride content. The six and twelve month acid soluble chloride profiles for the cyclic chloride and carbon dioxide exposure are shown in Fig. 7 as solid lines. The shape of these profiles differ significantly from the chloride only profiles. After an initial dip, the concentration plateaus for a significant distance before increasing to a peak which sharply declines toward zero again. The end point of the plateau and the peak generally progress into the concrete as the exposure duration increases. Again, the water soluble profiles are plotted as dotted lines (Fig. 7) and follow a similar trend to the acid soluble profiles.

\section{Discussion}

PH Profiles

The $\mathrm{pH}$ profiles principally illustrate the effectiveness of the drying regime at allowing carbonation to occur. It would appear that the depth of carbonation is limited by the drying depth which is accordingly limited by the drying time. In structures in which the concrete is exposed to predominately dry conditions and only periodically wetted, such as the underside of bridges or splash/atmospheric zones in marine structures, greater carbonation depths would be observed than in tidal zones where the concrete is more regularly wetted and therefore cannot dry out to as great a depth.

\section{Chloride Profiles}

The most apparent effect of cyclic exposure of the concrete to combined deterioration mechanisms can be observed in the chloride profiles of the cyclic chloride and carbon dioxide samples (Fig. 7). The distinct plateau followed by an increase in chloride concentration to a peak and then decrease to zero is most unlike what is observed in the chloride only exposure (Fig. 6). It is also not what would be expected from an external chloride source even accounting for the effects of wetting and drying. An explanation for this unusual profile can be obtained by overlaying the $\mathrm{pH}$ profiles onto the 
chloride graphs as in Fig. 7 where it can be observed that in there is a correlation between the $\mathrm{pH}$ and the chloride concentration. When the concrete is carbonated and the $\mathrm{pH}$ is low, the chloride concentration is correspondingly low; when the $\mathrm{pH}$ begins to rise again as the extent of concrete carbonated begins to decrease, the chloride concentration begins to rise also until it reaches its natural peak and decreases toward zero. It is known that Friedel's salts become unstable in carbonated concrete and chlorides are released (Suryavanshi et al. 1996), which would explain the lower total (acid soluble) chloride content; there will remain some difference between the acid and water soluble content due to residual Friedel's salts and physically bound chlorides. It would be expected that the free/water soluble chloride content would increase due to the influx of previously bound chlorides and the concentration converges toward that of the total/acid soluble content. However, this is not the case as both concentrations decrease when the concrete is carbonated.

Possible explanations for this phenomenon could be that:

- Calcium carbonate from carbonation is more voluminous than the calcium hydroxide that it consumed and would decrease the pore volume of the concrete. The decreased pore volume would hold less pore fluid and although the previously bound chlorides may increase the pore fluid chloride concentration, the decrease in volume means this is not proportionally represented as an increase in the water soluble chloride concentration.

- The chemical equilibrium (Kropp 1995; Neville 1995b; Nilsson 1996) means that a greater concentration cannot be chemically accommodated, so the free chlorides migrate deeper into the concrete.

\section{Penetration and Concentration of Chlorides}

Since the only the free chlorides are able to initiate corrosion, the water soluble profiles were used to derive values for the maximum depth of penetration, maximum depth of penetration of the critical chloride threshold (taken as $0.5 \%$ ), and the concentration at $25 \mathrm{~mm}$ depth. These depth and concentration values were then plotted on Figs. 8 and 9, respectively. The water soluble chloride concentrations at $25 \mathrm{~mm}$ are greater in the cyclic chloride and carbon dioxide exposure than the chloride only. When the concrete was carbonated, the previously chemically bound chlorides were released. This creates an increase in the concentration of water soluble chlorides in a smaller pore structure. The diffusion gradient also increases and drives the ingression of chlorides deeper into the concrete. This effect can also be seen in the greater maximum depth of penetration and depth of penetration of the critical chloride concentration in the cyclic chloride and carbon dioxide samples.

\section{Conclusion}

The introduction of carbon dioxide is known to release previously bound chlorides (Suryavanshi et al. 1996). When a structure is subjected to cycles of chloride and carbon dioxide, the carbonation of the concrete has been shown to increase the water soluble chloride concentrations and the depth of penetration of water soluble chlorides. This would increase the corrosion potential of reinforced concrete structure constructed using GGBS concrete. Subsequently, one of the most important factors affecting the corrosion of steel reinforcement is the concentration of free chlorides as they are responsible for active corrosion. While the total (acid soluble) chloride profiles were observed to have fluctuated more, the water soluble chloride profiles generally followed a smoother curve. Although quantification of the water soluble chlorides may be a more accurate way of assessing corrosion risk than total chlorides, it is a higher risk method as it does not account for the bound 
chlorides nor does it give an accurate representation of the actual free chloride concentration. Should conditions arise where carbonation is also experienced leading to the liberation of additional bound chlorides, there is potential for an increase in free chloride concentration in the material. When this information is considered in conjunction with the review of critical chloride concentrations by Angst et al. (2009) which highlights the wide variations in concentrations that have been found to induce corrosion, it is apparent that a more accurate, comprehensive method of quantifying the corrosion potential of a structure is required.

Further research involving a more comprehensive range of laboratory exposure scenarios with data from field structures would be recommended to develop a correlation and identify trends between laboratory and field results.

\section{References}

ACl (American Concrete Institute). (2011). "Building code requirements for structural concrete and commentary." ACl 318-11, Farmington Hills,

MI. Angst, U., Elsener, B., Larsen, C. K., and Vennesland, Ø. (2009). "Critical chloride content in reinforced concrete-A review." Cem. Concr. Res.,39(12), 1122-1138.

Arya, C., and Xu, Y. (1995). "Effect of cement type on chloride binding and corrosion of steel in concrete." Cem. Concr. Res., 25(4), 893-902.

Bamforth, P. B., Price, W. F., and Emerson, M. (1997). An international review of chloride ingress into structural concrete, TRL (Transport Research Laboratory), Wokingham, U.K.

Bostanci, Ş. C., Limbachiya, M., and Kew, H. (2015). "Portland slag and composites cement concrete: Engineering and durability properties."

J. Cleaner Prod., 12, 1-11. BSI (British Standards Institution). (1986). "Testing concrete-Part 125: Methods for mixing and sampling fresh concrete in the laboratory."

BS EN 8004, London. BSI (British Standards Institution). (2006). "Products and systems for the protection and repair of concrete structures-Test methods- Determination of carbonation depth in hardened concrete by the phenolphthalein method." BS EN 14630:2006, London.

BSI (British Standards Institution). (2007). "Products and systems for the protection and repair of concrete structures-Test methods - Determination of chloride content in hardened concrete." BS EN 14629, London.

BSI (British Standards Institution). (2009). "Testing hardened concrete- Part 2: Making and curing specimens for strength tests." BS EN 12390-2, London.

BSI (British Standards Institution). (2013). "Concrete. Specification, performance, production and conformity." BS EN 206, London.

Buenfeld, N. R., and Newman, J. B. (1984). "The permeability of concrete in a marine environment." Mag. Concr. Res., 36(127), 67-80.

Dhir, R. K., El-Mohr, M. A. K., and Dyer, T. D. (1996). "Chloride binding in GGBS concrete." Cem. Concr. Res., 26(12), 1767-1773. 
Glass, G. K., Reddy, B., and Buenfeld, N. R. (2000). "The participation of bound chloride in passive film breakdown on steel in concrete." Corros. Sci., 42(11), 2013-2021.

Go ni, S., and Guerrero, A. (2003). "Accelerated carbonation of Friedel's salt in calcium aluminate cement paste." Cem. Concr. Res., 33(1), 21-26.

Kropp, J. (1995). "Performance criteria for concrete durability." RILEM Rep. No. 12, Taylor \& Francis, London.

Lu, X., Li, C., and Zhang, H. (2002). "Relationship between the free and total chloride diffusivity in concrete." Cem. Concr. Res., 32(2), 1-7.

Luo, R., Cai, Y., Wang, C., and Huang, X. (2003). "Study of chloride binding and diffusion in GGBS concrete." Cem. Concr. Res., 31(1), 323-326.

McPolin, D. O., Basheer, P. A. M., Long, A. E., Grattan, K. T. V., and Sun, T. (2007). "New test method to obtain $\mathrm{pH}$ profiles due to carbonation of concretes containing supplementary." J. Mater. Civ. Eng., 10.1061/(ASCE)0899-1561(2007)19:11(936), 936-946.

Mehta, P. K., and Monteiro, P. J. M. (2006). Concrete, microstructures, properties, and materials, 3rd Ed., McGraw-Hill, New York.

Montemor,M. F., Cunha, M. P., Ferreira, M. G., and Simões, A. M. (2002). "Corrosion behaviour of rebars in fly ash mortar exposed to carbon dioxide and chlorides." Cem. Concr. Compos., 24(1), 4553.

Nagatakii, S., and Ohga, H. (1992). "Combined effect of carbonation and chloride on corrosion in fly ash concrete." Spec. Publ., 132, 227-244.

Neville, A. (1995a). "Chloride attack of reinforced concrete: An overview." Mater. Struct., 28(2), 6370.

Neville, A. M. (1995b). Properties of concrete, 4th Ed., Longman, Harlow, U.K.

Nilsson, L.-O. (1996). "Interaction between microclimate and concrete-A prerequisite for deterioration.” Constr. Build. Mater., 10(5), 301-308.

Osborne, G. J. (1999). "Durability of portland blast furnace slag cement concrete." Cem. Concr. Compos., 21(1), 11-21.

Parrott, L. J. (1987). A review of carbonation in reinforced concrete, BRE, Garston, U.K.

Polder, R. B., and Peelen,W. H. (2002). "Characterisation of chloride transport and reinforcement corrosion in concrete under cyclic wetting and drying by electrical resistivity." Cem. Concr. Compos., 24(5), 427-435.

Schiessl, P. (1988). Corrosion of steel in concrete, Chapman and Hall,London.

Suryavanshi, A. K., Scantlebury, J. D., and Lyon, S. B. (1996). "Mechanism of Friedel's salt formation in cements rich in tri-calcium aluminate." Cem. Concr. Res., 26(5), 717-727.

Suryavanshi, A. K., and Swamy, R. N. (1996). "Stability of Friedel's salt in carbonated concrete structural elements." Cem. Concr. Res., 26(5), 729-741.

Thomas, M. D. A., Hooton, R. D., Scott, A., and Zibara, H. (2012). "The effect of supplementary cementitious materials on chloride binding in hardened cement paste." Cem. Concr. Res., 42(1), 1-7. 
Tilly, G. P. (2011). "Durability of concrete repairs." Concrete repairs, M. Grantham, ed., Taylor and Francis, Oxford, U.K..

Tilly, G. P., and Jacobs, J. (2007). Concrete repairs: Performance in service and current practice, BRE, Garston, U.K.

Ye, H., Jin, N., Jin, X., and Fu, C. (2012). "Model of chloride penetration into cracked concrete subject to drying-wetting cycles." Constr. Build. Mater., 36, 259-269.

Yuan, Q., Shi, C., De Schutter, G., Audenaert, K., and Deng, D. (2009). "Chloride binding of cementbased materials subjected to external chloride environment-A review." Constr. Build. Mater., 23(1), 1-13. 